\title{
Social representations of health professionals about terminally ill children and adolescents
}

Fernanda de Souza Fernandes ${ }^{(1)}$ Fabiane Ferraz $^{(1)}$

Giovana Ilka Jacinto Salvaro(1) Amanda Castro ${ }^{(1)}$ Jacks Soratto ${ }^{(1)}$

(1) Universidade do Extremo Sul Catarinense - UNESC, Criciúma, Santa Catarina, Brasil.

Conflict of interests: Nonexistent

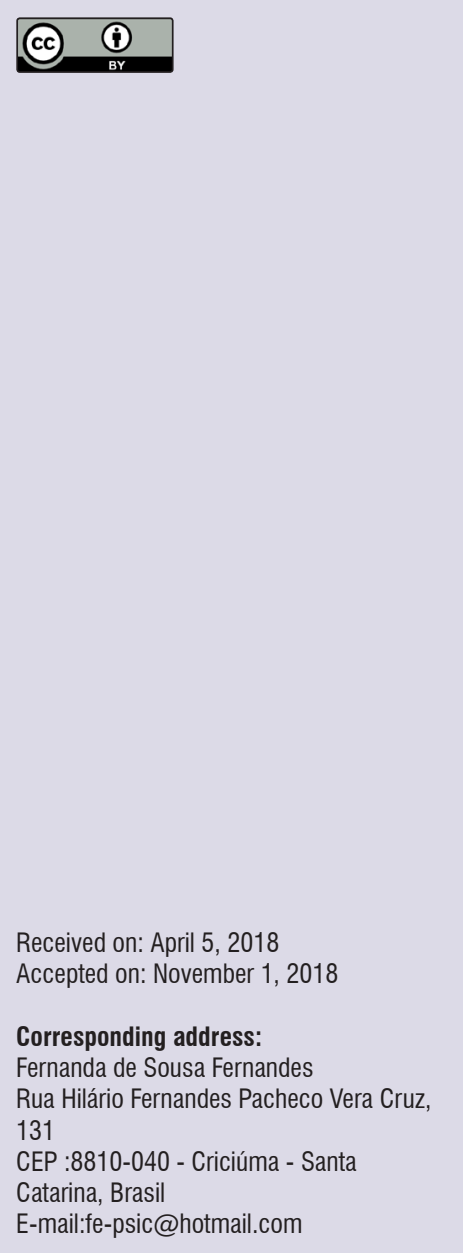

\section{ABSTRACT}

Purpose: to understand the social representations of health professionals about terminally ill children and adolescents in different work settings.

Methods: a qualitative, descriptive, exploratory study was conducted with ten health professionals, selected through the technique of network sampling. The instruments for data collection were semi-structured interviews, and free association of words. The analysis of the data followed the steps of content analysis, subsidized by the theory of social representations, with the support of Atlas.ti software.

Results: the analysis of the interviews presented 115 excerpts of statements, condensed into 11 codes, which were grouped into three categories: experiences, strategies, and consequences of conviviality with terminality; mission and amorousness in a terminal condition; terminality as the end of life. The free association of words resulted in 52 evocations, with an emphasis on suffering, pain, love, mission, and family.

Conclusion: the social representations of health professionals about terminally ill children and adolescents are associated with the situations being experienced, the strategies developed to deal with these moments in the exercise of the profession, and the consequences that this experience causes in the health professionals.

Keywords: Palliative Care; Hospice Care; Terminally III; Child Care; Integrality in Health 


\section{INTRODUCTION}

It is estimated that some 600 thousand new cases of cancer will occur in Brazil next year, across all age groups. This situation will require a governmental response for managing policies and more qualified professional practice to provide care for people in situations of chronic and terminal illness.

In view of this scenario of increased neoplasms, children and adolescents are of central importance, with a median percentage of pediatric tumors observed in the population-based cancer registries of Brazilians that is close to $3 \%$. Therefore, approximately 12,600 new cases of cancer will occur in children and adolescents, up to the age of 19 .

The chances of cure of childhood cancers is about $70 \%$, when the disease is discovered early; however, $30 \%$ of the cases need palliative care because of the end of life. In these cases, the resulting conditions may be associated to the type or stage of the disease ${ }^{1}$.

The dying process should be valued, with care being provided that offers the maximum quality of life to dying child, as well as those who are involved ${ }^{2,3}$.

The World Health Organization (WHO), sates that palliative care should be started when the chronic disease is diagnosed, in parallel to the curative treatment. The evaluation and relief of suffering are priorities of this approach, and must go beyond the biological arena, reaching the psychological and social spheres ${ }^{4-6}$.

In the daily work with terminal conditions, some challenges go beyond technical practice; among these are feelings of powerlessness, lack of emotional involvement, conformism, compassion, identification with the dying person and his relatives, failure, and lack of academic preparation for facing death ${ }^{5,6}$.

Based on the above, and with experience in the academic and professional scenarios, the following research question was raised: What are the social representations of health professionals about terminal conditions of children and adolescents? Representations are a theory of social psychology that is concerned with studying the development of ideas, images, conceptions, and worldviews those social groups has about reality, and which can be manifested by behaviors. Therefore, the objective of this research is to understand the social representations of health professionals about the terminally ill children and adolescents.

\section{METHODS}

The data collection for this study met all the recommended ethical precepts for research with human beings, and was conducted after authorization of the responsible bodies, and by the Ethics Committee of the University of Extremo Sul Catarinense-UNESC, with opinion number: 2.157.987CAAE:70028217.7.0000.0119. Participants' free participation was guaranteed, along with anonymity which was guaranteed by means of an alphanumeric code consisting of the letter $P$, which typified the participant, and a number assigned to the sequence of the respondent, for example: P1.

This was a descriptive exploratory study, with a qualitative approach, ${ }^{6}$ as outlined by the National Humanization Policy ${ }^{7}$ and by the theoretical reflections on social representations ${ }^{8,9}$.

The present study was conducted in the city of Criciúma, in southern Santa Catarina State in Brazil, with health professionals who work or had worked with terminally ill children and adolescents. Ten health professionals were included, namely: nurse [3], psychologist [3], physician [1], nutritionist [1], social worker [1], and nursing technician [1]. The number of participants was considered sufficient according to the criterion of saturation ${ }^{10}$.

The selection of participants for data collecting occurred through network sampling or snowball technique ${ }^{10}$. The network sampling process occurred as follows: recruitment of a key-informant, using an announcement in social networks, and providing the email contacts of the involved researchers. Fifteen interested professionals were obtained, and three informants were selected to be participants of the study. After the key-informant was selected, new contacts were indicated from his own personal network of knowledge, with the required characteristics. Finally, contact was established with the individuals indicated by the informant, in order to confirm compliance with the selection criteria.

Figure 1 shows the process of selecting study participants. 


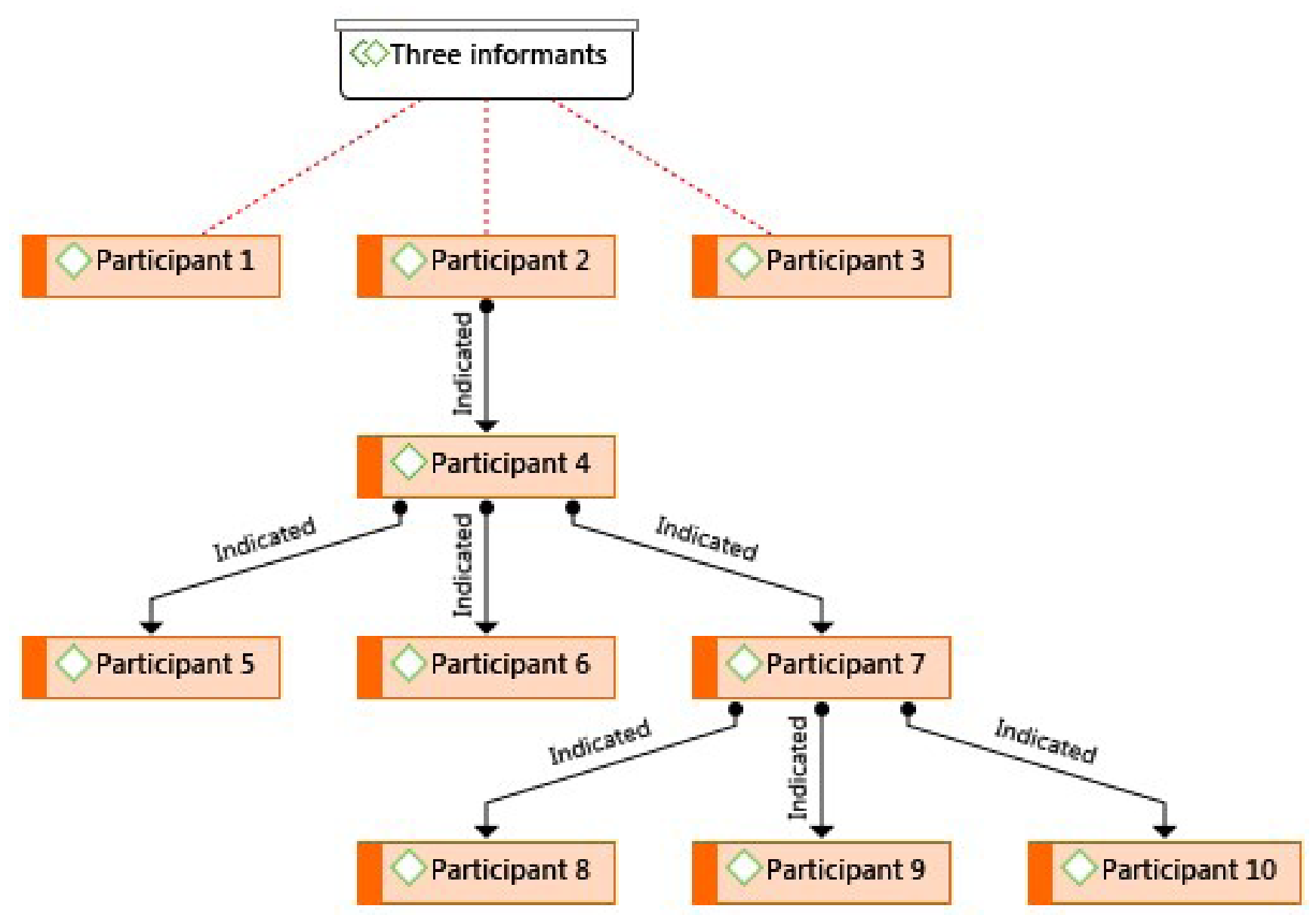

Source: Data obtained by research

Figure 1. Selection of the research participants

Data collection was conducted using two techniques employed in qualitative studies: a semi-structured interview as the main instrument, and associative network or free association of words (FAW) as a complementary tool. The interviews were performed between July 1 and October 1, 2017 at a place and time defined by the participants, using a script composed of 14 questions: seven closed to identify the profile of the participants, and seven open questions with emphasis on the object of this study. The FAW was materialized through a word cloud, to strengthen the findings from the semi-structured interviews.

At the place where the data were collected, the research objective was presented and the participants signed the Terms of Free and Informed Consent form, which contained information about the research, and the rights of the participants. All the interviews were recorded, totaling 318 minutes and 20 seconds; they were transcribed and validated by the participants by e-mail.
The data were organized according to the precepts of content analysis, which is divided into three phases: pre-analysis, material exploration, and interpretation ${ }^{11}$. Analysis was supported by Atlas.ti qualitative data analysis software. The relationship between content analysis and the software was introduced through the inputting of the interviews (documents), selection of excerpts from narratives (quotations), coding (codes), grouping of codes (codes), extraction of results (outputs), and generation of the word cloud (word cloud).

\section{RESULTS}

The results indicated the existence of 115 excerpts from narratives, condensed into 11 codes, which were grouped into three categories. Expressions that were coded with one or more codes were selected; these will be highlighted in the discussion to enable a better understanding by the readers, articulating the theory, and perception of the researchers. 
The first category, experiences, strategies and consequences of living with terminality, was subdivided into three subcategories: experiences with situations involving terminal conditions, which had the following codes: feeling of failure [20]; team limitations [9]; and sense of accomplishment [12], totaling 41 excerpts of narratives; strategies of overcoming living with terminal conditions, which had the following codes: self-improvement [12] and religiosity [19], totaling 31 excerpts of narratives; consequences of experiencing situations of terminal conditions, which had the following codes, extending the meaning of life [5], and personal learning [12], totaling 19 excerpts of narratives.

Next, the category, mission and amorousness in a terminal situation had the following codes: manifestation of mission [7] and manifestation of love [6], totaling 13 excerpts of narratives.

The third and last category, end of life, had the following codes: terminality and premature interruption of life [8] and death [5], totaling 12 excerpts of narratives.

The next table summarizes the findings of the study:

Table 1. Description of categories and codes based on the number of excerpts from narratives related to social representations of terminally ill children and adolescents

\begin{tabular}{lccc}
\hline Categories & Codes & n & \% \\
\hline & Failure & 20 & 17.4 \\
Experiences, strategies and consequences of & Religiosity & 19 & 16.5 \\
conviviality with terminal illness & Personal learning & 12 & 10.4 \\
& Self-overcoming & 12 & 10.4 \\
\multirow{2}{*}{ Mission and amorousness in the terminal } & Sense of accomplishment & 12 & 10.4 \\
conditions & Extending the meaning of life & 9 & 7.8 \\
Terminal conditions as the end of life & Team limitations & 5 & 4.3 \\
& Manifestation of mission & 7 & 6.1 \\
Total & Manifestation of love & 6 & 5.2 \\
\hline
\end{tabular}

Source: Data obtained by research.

In order to strengthen the interview findings, the FAW was performed, which totaled 32 words, with 52 evocations, and followed a spiral format, where the words that were most numerous [pain, suffering, and love] were in the center, and the others in the outer rings representing the words with lowest repetition frequency. The following figure illustrates this relationship: 


\section{strength}

\section{imosenente Suffering loss hope learning incredulity

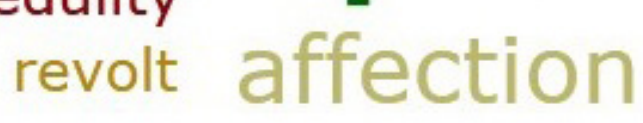 emptyness \\ future family sadness ${ }^{\text {will }}$ mission}

Source: Data obtained by research

Figure 2. Words evoked by health professionals related to terminally ill children and adolescents

\section{DISCUSSION}

\section{Experiences, strategies and consequences of conviviality with terminal illness}

The experiences seem to pass through the development of potentialities or abilities that the professional broadens in dealing with the terminally ill and also the fragilities or difficulties often sustained by withdrawal or avoidance, and/or feelings of powerlessness associated with the idea of failure when caring for terminally ill children and adolescents, which are manifested in an attempt to avoid death of the patient ${ }^{5,12}$.

The statements of the following participants show these experiences associated with feelings of avoidance, withdrawal, and powerlessness.

[...] sometimes you want to do something and you cannot; I'm speaking as a social worker of an institution; we would like to seek any resources to save them. So, there are many things, very good in theory, but in practice, even if you have money; what would you do? (P10).

The feeling of powerlessness, failure, with the sense that one should be able to do something else was also seen in the evocation of words when they mentioned: pain [6], suffering [5], sadness [2], disbelief [1], incredulity [1], nonsense, [1], ending [1], expressing how deeply rooted the idea of terminal conditions and death is as a transmitter of negativity. Social representations also emerge as a manner of providing a symbolic value, aiming to understand a particular object, to define it, to give it identity ${ }^{8,9}$.

When talking about statements, according to the theory of social representations, to anchor is to classify or to name something ${ }^{8,9}$. The statements of the participants identified the materialization of the process of terminal conditions and death, supported by the feeling of powerlessness and failure that emerges with pain and suffering. They glimpse the obligation to care with presence, to be together at the moment when life reserves the great challenge of farewell. The presence and the listening performed by the professional are fundamental for relieving suffering at the moment of death, and reach spaces of the human dimension that no form of medication can access ${ }^{12-14}$.

The health professional who does not confront his own death will have difficulties in understanding the other's death [the one he is caring for] and, consequently, caring for those in a terminal condition will become challenging ${ }^{13}$. In addition, these fragilities may camouflage themselves as a necessity for withdrawal 
and avoidance, turning into a feeling of failure and powerlessness.

In the work environment, a safe space created in the relationship between the team members is needed. Research participants also mentioned weaknesses that appeared as limitations of some team members, in dealing with terminal illness in children, as described below:

The difficulty I have sometimes is with other individuals that interfere in this moment, and to contain these other people is a little difficult, I cannot be very incisive at this moment; sometimes I want to cut the corners, but I can't (P5).

Another major difficulty is that the team has no structure to handle it, no one knows how to do that. At the same time, there is a human being there, in despair, shock, needing a caress, to be cherished, that has no word and no gesture, so I acted with my heart. Without technique, but with a heart, with a very open heart (P4).

The lack of preparation of the health team in dealing with terminal situations can generate consequences. Although they have received technical preparation to provide care, in place of their own feelings, emerging from witnessing the suffering of children and families receiving care in the terminal process, professionals may present difficulties that will reflect in the care system that needs to be in tune with needs [physical, social, family, psychological, and spiritual] of the patient and his/her family.

There was a feeling of being useful, beneficial, and of being present, in addition to the sensation of peace emitted by the interpretation that the patient was at rest, that in spite of the farewell of the patient, there was a liberation of the bonds of pain and agony. The following statements represent the findings on the representations of terminal conditions as the accomplishment of a duty:

It is easy to see that they have stopped suffering, I think they have gone to a better place; that we try to comfort ourselves in this manner, in thinking that the suffering is over (P7).

[...] And at the same time, it was as I could say, very beautiful; so despite the pain of that situation, seeing the mother's strength, the mother's potency of being independent of everything, until the last breath: [example] I'm with my child and I do what I have to do; that situation was remarkable for me, a lot. It was strong for me, it was the one that was the most incredible (P6).

Experiences with terminal illness and the approximation of death can also teach great lessons ${ }^{13}$. After the patient dies, if the practitioner has listened to him, cared for him holistically, with interventions to relieve his moments of pain, he will feel at ease during the next days, feeling the peace of good work having been done.

The challenges required daily for the practice of palliative care, in the face of the process of relationship with the family members, make the professional's desire for offering care intense, as demonstrated in his work technique, and the sense of love for this work.

From this, the sense of accomplishment emerges, which supports the professional and personal contentment in the practice of care. This leads to the philosophy of palliative care that guides provision of health care practices with dignity, especially with regard to this approach to the dying process:

[...] which improves the quality of life of patients and families facing problems associated with life-threatening diseases, by means of prevention and relief of suffering using early identification, correct assessment and treatment of pain and other physical, psychosocial, I and spiritual problems ${ }^{4}$ (p. 84).

Strategies are needed to deal with this daily life, in which the health professional has access to the excessive demand of feelings that emerge at each stage of terminal illnesses of children and adolescents, linked to self-improvement that appears in a triad, that is, linked to the sense of care, withdrawal or avoidance and religiosity. The words expressed that are linked to this category were: hope [2], perseverance [1], faith [1], trust [1], and strength [1].

Overcoming oneself refers to a force that drives the human being to create alternatives that generate satisfaction. The self-overcoming in the sense of caring is clear for the interviewees P5 and P2, who, at the moment of the patient's farewell, seek to overcome their pain [remaining in the sense of care] showing strength, abstaining from their suffering, opening up possibilities of space for the family to experience its pain.

I think that this is an ease of mine, to understand that this is a family moment, it's not my moment, it is not the moment of anyone else, it is theirs, so I have to abstain from that moment (P5). 
You often need to dress up as a strong person. How many times do you go to the patient room and you are crying as you leave the room. So, I guess that's it, I think that sometimes you develop a certain barrier to not fade away totally in front of that family member (P2).

The environment of suffering and pain is something that emerges in the health professionals who care for terminal patients, as in most of these moments it is forbidden for the professional to express his pain, because some cannot recognize it, and in others the fear of being misunderstood is present 5,12 .

The statement of the participants showed a tendency for overcoming oneself that directs them to care, but at the same time, their suffering exists, suppressed by avoidance of feeling the grief. This possibly generates a disconnection, not from the patient and of the family, but from oneself, as "[...] representation equates every image with an idea and every idea with an image" 8 (p. 46).

On the other hand, frailties, uncertainties, vulnerabilities, etc., can emerge if the professional accesses the mechanism of escaping from feeling because of a fear of connection with what death negatively represents to him. The individual does not choose to feel, or he does not agree to express or share what he is feeling, during every moment of professional activity. In these cases many discomforts or even physical and emotional illness can be unavoidable, as described by participant P8:

And I was upset [anxious], got tachycardia, kept thinking about the child, all the time. Until I got used to it. Well, I ended up getting out of there and did not get used to it. [...] Because whether they want it or not, they need strength, if you cry a day with a father or a child they will cry with you, but if you show yourself strong around them, they will stimulate themselves, they will feel stronger (P8).

The disregard for feelings related to mourning are demonstrated as an escape strategy, which may be reinforced by learning during education, which often teaches that non-involvement with the patient and the patient's family will protect the professional. However, unconscious defense mechanisms may arise, with the potential to transform into psychosomatizations, which over time may lead to significant health problems for the professional ${ }^{13}$.

Another aspect present in the representations of the participants in relation to the strategies of conviviality with the dying process was religiosity, which arose as a commitment of the professionals to make the crossing by the coexistence of dying and death, with the conditions necessary to help the children and the family to pass through the moment of farewell in a most dignified form. The attempts linked to the search for meaning for terminality linked to religiosity are present in the following statements:

I work my faith, I work my faith because having faith in God, to seek a better answer, then we always seek an answer to comfort us, if he/she did not remain with us, it is because there is something better, because was a good person to stay on earth suffering? So, I try to work my faith, and strengthen my faith and my relationship with God (P10).

[...] for not having a child and for having this doctrine [Spiritualist Doctrine], I think that I don't understand it as I'm not seeing them again. For me it's as if they had gone to travel, in a moment, it's a crazy way of thinking, I think that I search my spirituality (P6).

Considering the aspects of the idea of the divine, of religiosity as a strategy of overcoming oneself, the participants associated dying and death of the children to celestial images. Professionals typified and associated the moment of the child's terminal illness and death as a transitional moment when children become celestial beings, as described in the statements of participants P1, P2, P6 and P10.

I think it has no better figure than the figure of an angel, a little angel (P1).

Comfortable little angels (P2).

An angel, a pretty angel with very large wings like that. [opening arms] (P6).

Because I think they are angels. Because I think that they will be in a better place than in this life, that they have been suffering enough, they go through so many bad things, right? (P7).

The death of the child, an angel, an angel of light (P10).

The thought represented in the angel's image also seems to be linked to the idea of professionals that the child is born with a mission [as a missionary angel] to transform lives or to pass a divine ordeal. In addition to contributing to her humanity, it makes her more kind and empathetic, in order to deserve eternal life. According to this, it is reflected that the participants, the 
children, when their journey through the life they had has finished, they did not actually die, but continued in the form of an angel.

The hope that transits through all the phases of the pain of departure and of mourning, in the initial stages enables the expectation of a cure, even if it is impossible. And in the last moments of life, hope leads to the possibility of reunion in a probable heaven, according to the religious meaning of each person.

The consequences of the experience with terminal conditions for the professionals of this study are full of meaning; life and living that reproduce an understanding of their own life and its living, and collaborate for their social representations.

On this question, the research participants mentioned that living with the terminal conditions presented them with the expansion of the meaning of life and personal learning. In the involvement, in a close relationship with the children and their relatives, learning occurred in the encounter and coexistence, according to the statements of P10, P9 and P7 who expressed the representations of terminal conditions as changes in the sense of life and learning:

Surely, we start giving value to the little things in life because we are seeing children, adolescents, who have no sin going through all that there, and how happy they are with simple things when they are inside the hospital being stuck with needles, when they are out and even inside the hospital; many times I got there to pay a visit and they were smiling. Then, they can be in so much pain, but not expressing a smile is very difficult; they always have something good. So, I value the simplest things in life (P10).

[...] Very much, I began to give more value to my life, to small moments, small situations, to listen more to people (P9).

The professionals who experience the departure of their patients are able to feel the life present in this passage, that is, to give meaning to the life that transgresses the windows of this existence, learn from the experience of death of the other and develop the tendency to rethink their values in regards to the way of feeling and living life. Together with the development and redevelopment of the sense of living, the professionals stated that their coexistence with terminal conditions contributed to the opportunity to learn in depth, transforming the meaning regarding their everyday experiences, attributing greater value to the simple situations of life as observed in the statements of P2 and P8.

I think it's a way of learning, I think that those who work in the health field always end up creating a shield, sometimes even a little mechanized, because you know that our life is a cycle, we are born, grow, live and then death comes. So you always try to stay on the good side of death, but I think it's always a preparation, I think you end up getting a little stronger because you've been through all this experience [...] (P2).

I started to see the life, not just of a child, but of adult, as well. Because we sometimes complain: here, this again? But what I saw, the patient came from far away, often with the trachea and throat all open because he had a tube, etc. It was there that I saw life differently (P8).

Health professionals who work with the terminally ill need a space where they can feel heard and connect in a safe way, with their personal stories of loss, and then legitimize the experience of mourning that they will certainly live by caring for patients in the process of departing this life.

The awareness of personal loss, as well as enabling them to produce new meanings and learning about life, living and death, can promote and expand their professional skills and their personal life.

Regarding the consequences of the experience with the terminally ill children and adolescents for the participants of this study, with respect to the expressions in the words evoked during the word cloud exercise, they reinforce the set of meanings presented throughout the interview, namely: learning [2], hope [2], support [1], growth [1], strength [1], future [1], perseverance [1], life [1], and will [1].

In social representations theory (SRT) lies the human being, able to move in search of understanding the world and the reality around him. He appropriates social reality, and internalizes what can be shared in his surroundings with all those that are part of his world ${ }^{8,9}$.

\section{Mission and amorousness in terminal conditions}

The expression that includes the mission in this research refers to the way the health professionals understand the suffering of children and families in the face of terminality and death. On this aspect, the statements of the health professionals P1 and P2 are presented. 
I think that what he/she [the child] has to do here, the task he/she has to accomplish is so small, it is so little what he still desires, but what he has left to finish in this life, he/she comes to spend this very short period with us and goes, he concludes and goes (P1).

Everything that we spend on earth comes to us for a mission, either for our family or for our spirit. And the purity and innocence of children because they often do not understand that whole process, what is happening, so he/she is innocent throughout the whole process (P2).

Giving a sense of mission to the process lived by children seems therefore inevitable, although one might expect other feelings to be associated with this idea. But the professional continues to accommodate all this, seeking understanding, often based on knowledge acquired and related to his spiritual path or his religiosity ${ }^{13,14}$.

The evoked words that were associated with love and mission were: love [4], affection [2], comfort [2], family [2], mission [2], attention [1], kindness [1], compassion[1], and trust [1]. These findings are related to SRT, knowing that for the development of the social representations, the theory transits by the individual and these are developed collectively. In terms of mission and the terminally ill, the theory conducts the argument that the ideas materialized in words, shared among this social group, enable anchoring and objectification.

The idea that terminal conditions is a process of proof and mission is anchored in the field of ideas and meanings that, when characterized, materialized and transformed into words, comprise objectification. This will describe a part of the set of other representations about terminally ill children and adolescents who compose this study ${ }^{8,9}$. Loving, in this process, seems to be identified precisely by relationship of affection and love established between the professional, the patient, and the family, and explanations about the feelings emerging from these experiences.

With regard to the understanding that the terminal conditions process evidences, from the participants' statements, one can identify the need to give meaning to the scenario of the terminal illness, of which these professionals are also a part. In the scenario with the terminal illness is the need to accommodate those feelings that emerge from the experience, until acceptance occurs.
In acceptance, although it may be confused with a moment of relief and happiness, this state is in fact a time when there is "[...] almost an escape from feeling. It is as if the pain had faded, the struggle had ceased, and the moment of ultimate rest was coming before the great journey" ${ }^{14}$ (p. 118).

The acceptance of health professionals seems to be developed from the relationship of amorousness established among those involved in the dying process, as indicated by participants $\mathrm{P} 4$ and P9.

[...] and then you realize that this [death] is a relief for that little being there, for that family, it is a liberation from a suffering, a pain. And that's not bad, so when I look at that, I can try to at least understand, and it makes me feel better, knowing that somehow, in a small manner, with a small gesture I could contribute to a process of growth. That's what makes me feel better (P4).

Dying is a period of life in which the person needs some comfort of the family, needs the confidence of the professional, needs to be integrated into an environment of love to be able to go through that, which is one thing, a phase that cannot be avoided or cannot pass, in the case of children and adolescents who will go through that in a more gentle manner (P9).

To connect with this relationship is to be able to perceive the love that pulsates in life, even when life is ending its course in dying or death.

[...] this is to work hard on the issue of love, because this is a moment of attachment of the mother to the child, it is a very loving relationship. And that is greatly enhanced depending on the timing of the disease. What I can say, is that is a sui generis moment, there is no such thing, and there is nothing in the world that can be compared to that moment. So, I see it as a very rich moment, for which no one is prepared, and that each situation is different, because it will depend on the mother and that child, of course on the other actors who are involved, such as the father, a brother, but it is usually more of this dynamic of the child with the mother. But despite the entire emotional load present in that situation, I understand it as a very rich moment. And what we can bring and emerges a lot there is a lot of emotion that can be productive for that family that will survive that loss [...] (P5). 


\section{Terminal conditions as the end of life}

In the P2 interviewee's understanding, terminal conditions and death are associated with the interruption of a life cycle, this interruption is full of anguish and denial, that this process is part of nature, and therefore also human.

I think it's a sad thing. It is nonetheless. I think that at any stage of life, death is sad, when you see a child, who would have all his life ahead, adolescence, adulthood, that he/she could become a father/mother, contribute to the development of the society, so I guess you end up visualizing a sadness, because he/she was interrupted very young, that long way he/she would have to go (P2).

In this sense, death is one of the stages present in the process that is usually called terminal conditions. It was observed that there are professionals believing that terminality refers to the anticipation of death. Participants P10 and P8, even when they are in contact with terminal conditions, and therefore, they realize they are providing care during moments of deep suffering of the patient and the family, and the child's death is being announced, the professionals seem to anticipate the suffering and mourning, that is, they mourn in advance.

Terminal conditions is the death right? [...] I think it's an exhausting period of anguish, knowing that there is no longer any recourse to be made by the physicians here on earth, we always believe that God can do a miracle. But the physicians do not have more to do and you see the suffering, at any time. For example, you stay in such anguish, he/ she's better, or not. Then sometimes the child has an improvement, you are happy, and soon he/she is bad again. I say that when this happens it is an early funeral, you don't want to, but you are seeing that this is what will happen (P10).

Loss is considered a situation that generates potential suffering in the individuals who are living it, in general the pain intensity of this separation [among other factors of the relationship] will be related to the importance of the existing link with what was lost 5,12. Compassion is a precious tool for supporting human pain and suffering. According to the phenomenological view, sufferings are seen as painful symptoms and, therefore, require urgent intervention on the part of health professionals ${ }^{5,13}$.

Humanization policies have emerged with the aim of enabling health professionals to intervene in the process of transcending technologies that bureaucratize and harden, that is, humanize the task of care ${ }^{7}$. In this area of work, where love and pain are constantly intertwined, professionals need to be understood and welcomed in what concerns this complex of symbolic and social representations in which terminality and death are present ${ }^{4,5,7}$.

Somehow, they are demonstrated in the day-to-day, in the form of personal or professional fragilities. And they emerge because of the feeling of helplessness and failure due to the impossibility of avoiding death. In addition, there is the number of potentials developed in the opportunity to live with the experiences of affection, love, bond, hope, and faith of the patients and their loved ones during their crossing through the dying and death. In this category we associate the following evoked words: love [4], mission accomplished [2], affection [2], compassion [1], faith [1], life [1], ending [1], and future [1]. These words reinforce the meanings that the professionals give to the scenario of terminal conditions to cross it, occupying the place of caretakers, participating in scenes that will never be forgotten.

Therefore, it is argued that health professionals should be given the opportunity to be prepared by means of information on the importance of the search for self-care, and education for understanding the death of children and adolescents, and death as a stage of life. In order to achieve better preparation to provide care for a life in the transition of dying and death with humanity and competence.

\section{CONCLUSION}

The social representations of health professionals about terminally ill children and adolescents are related to feelings of failure and grieving that lead them to develop strategies associated with overcoming oneself and religiosity.

In the delivery of care, professionals are linked to patients and their families, and connected with the love. And, they perceive the dying process as an unavoidable moment that happens through the accomplishment of the mission.

Working with terminally ill children and adolescents generates a mixture of pain, suffering, and love in the health professionals, and enables the reconnection with their essence of humanity through situations that daily evidence the finitude of life. 


\section{ACKNOWLEDGEMENTS}

To the health professionals participating in this research.

\section{REFERENCES}

1. Brasil. Ministério da Saúde. O que é câncer. Rio de Janeiro: INCA; 2016.

2. Felix ZC, Costa SFG, Alves AMPM, Andrade CG, Duarte MCS, Brito FM. Eutanásia, distanásia e ortotanásia: revisão integrativa da literatura. Ciênc. saúde coletiva. 2013;18(9):2733-46.

3. World Health Organization. Cancer pain relief and palliative care in children. Geneva: WHO, 1998.

4. Pessini L, Bertachini L. (orgs). Humanização e cuidados paliativos. 6. ed. São Paulo: EDUNISC/ Edições Loyola; 2014.

5. Kovác MJ. A caminho da morte com dignidade no século XXI. Rev. Bioét. 2014;22(1):94-104.

6. Morse JM. Critical analysis of strategies for determining rigor in qualitative inquiry. Qual Health Res. 2015;25(9):1212-22.

7. Martins CP, Luzio CA. Política humaniza SUS: ancorar um navio no espaço. Interface. 2016;21(60):13-22.

8. Moscovici S. Representações sociais: investigações em psicologia social. Petrópolis: Vozes, 2011.

9. Martinez EA, Tocantins FR, Souza SR. The specificities of communication in child nursing care. Rev gaucha enferm. 2013;34(1):37-44.

10. Minayo MCS. Amostragem e saturação em pesquisa qualitativa: consensos e controvérsias Rev Pesquisa Qualit. 2017;5(7):1-12.

11. Friese S, Soratto J, Pires D. Carrying out a computer-aided thematic content analysis with ATLAS.ti. IWMI Working Papers. v.18, n.2. Abril 2018. Disponível em: https://www.researchgate. net/publication/324720405. Acesso em:19 Jun. 2018.

12. Scannavino CS, Sorato DB, Lima MP, Franco AHJ, Martins MP, Morais Júnior JC et al. Psico-oncologia: atuação do psicólogo no Hospital de Câncer de Barretos. Psicol. 2013;24(1):35-54.

13. Silva AF, Issi HB, Motta MGC, Botene DZA. Cuidados paliativos em oncologia pediátrica: percepções, saberes e práticas na perspectiva da equipe multiprofissional. Rev: Gaúcha Enferm. 2015;36(2):56-62.
14. Clauduro ML, Custódio SAM. O processo de fase terminal (morte/luto) com familiares de pacientes oncologicos pós-óbito e a atuação do serviço social. RIPE. 2016;14(25):1-74. 